\title{
Prognosis of gastric cancer patients with node-negative metastasis following curative resection: Outcomes of the survival and recurrence
}

\author{
Jingyu Deng $M D^{1}$, Han Liang $M D^{1}$, Dan Sun $M S^{2}$, Rupeng Zhang $M D^{1}$, Hongjie Zhan $M D^{1}$, Xiaona Wang $P h D^{1}$
}

\begin{abstract}
J Deng, H Liang, D Sun, R Zhang, H Zhan, X Wang. Prognosis of gastric cancer patients with node-negative metastasis following curative resection: Outcomes of the survival and recurrence. Can J Gastroenterol 2008;22(10):835-839.
\end{abstract}

BACKGROUND: The purpose of the present study was to provide valuable prognostic information on lymph node-negative gastric cancer patients following curative resection.

METHODS: Data from 112 lymph node-negative gastric cancer patients who underwent curative resection were reviewed to identify the independent factors of overall survival and recurrence.

RESULTS: The five-year survival rate of lymph node-negative gastric cancer patients was $85.7 \%$, and recurrence was identified in 25 patients after curative surgery. The five-year survival rate of lymph node-negative gastric cancer patients was higher than that of lymph node-positive gastric cancer patients $(\mathrm{P}<0.001)$. Recurrence in lymph node-negative gastric cancer patients was less than that of lymph node-positive gastric cancer patients $(\mathrm{P}=0.001)$. The median survival after recurrence of lymph node-negative gastric cancer patients was longer than that of lymph node-positive gastric cancer patients $(\mathrm{P}=0.021)$. Using multivariate analyses, the following results were determined for lymph node-negative gastric cancer patients: sex, operative type and the presence of serosal involvement were independent factors of overall survival; and lymphadenectomy, number of dissected nodes and the presence of serosal involvement were independent factors of recurrence.

CONCLUSIONS: The prognosis of lymph node-negative gastric cancer patients was better than that of lymph node-positive gastric cancer patients. Male sex, subtotal gastrectomy and nonserosal involvement should be considered to be the favourable predictors of postoperative long-term survival of lymph node-negative gastric cancer patients. Conversely, limited lymphadenectomy, few dissected nodes and serosal involvement should be considered to be risk factors of postoperative recurrence of lymph node-negative gastric cancer patients.

Key Words: Gastric cancer; Lymph node metastasis; Multivariate analysis; Overall survival
Le pronostic des patients atteints d'un cancer gastrique sans atteinte des ganglions après une résection curative : Les issues de la survie et de la récurrence

HISTORIQUE : La présente étude visait à fournir de l'information pronostique intéressante sur les patients souffrant d'un cancer gastrique sans atteinte des ganglions lymphatiques après une résection curative. MÉTHODOLOGIE : Les données colligées auprès de 112 patients souffrant d'un cancer gastrique sans atteinte des ganglions lymphatiques qui avaient subi une résection curative ont fait l'objet d'une analyse afin de repérer les facteurs indépendants de survie et de récurrence globales.

RÉSULTATS : Le taux de survie des patients souffrant d'un cancer gastrique sans atteinte des ganglions lymphatiques au bout de cinq ans s'élevait à $85,7 \%$, et on observait une récurrence chez 25 patients après une opération curative. Le taux de survie au bout de cinq ans des patients souffrant de ce type de cancer était supérieur à celui des patients atteints d'un cancer gastrique touchant les ganglions lymphatiques $(\mathrm{P}<0,001)$. Chez les patients souffrant d'un cancer gastrique sans atteinte des ganglions lymphatiques, la récurrence était plus faible que chez ceux dont le cancer gastrique touchait les ganglions lymphatiques $(\mathrm{P}=0,001)$. La survie médiane des patients souffrant d'un cancer gastrique sans atteinte des ganglions lymphatiques après une récurrence était plus longue que celle des patients chez qui les ganglions lymphatiques étaient touchés $(\mathrm{P}=0,021)$. Au moyen d'analyses multivariées, les auteurs ont obtenu les résultats suivants pour les patients souffrant d'un cancer gastrique sans atteinte des ganglions lymphatiques : le sexe, le type d'opération et la présence d'une atteinte séreuse étaient des facteurs indépendants de la survie globale, tandis que la lymphadénoctomie, le nombre de ganglions disséqués et la présence d'une atteinte séreuse étaient des facteurs indépendants de récurrence.

CONCLUSIONS : Le pronostic des patients souffrant d'un cancer gastrique sans atteinte des ganglions lymphatiques était plus positif que celui des patients dont les ganglions lymphatiques étaient touchés. Le sexe masculin, la gastrectomie subtotale et l'atteinte non séreuse doivent être perçus comme des prédicteurs favorables d'une longue survie postopératoire pour les patients souffrant d'un cancer gastrique sans atteinte des ganglions lymphatiques. Par contre, une lymphadénoctomie limitée, peu de ganglions disséqués et l'atteinte séreuse doivent être perçus comme des facteurs de risque de récurrence postopératoire chez ces patients.
Gastric cancer, the most common malignancy in the world, J frequently reveals lymph node, peritoneum and liver metastases. More than one-half of gastric cancer patients have lymph node metastasis when they are initially diagnosed or operated on, which results in a poor prognosis (1-4). Lymph node involvement is the most important indicator of overall survival (OS) of gastric cancer patients following curative resection, and the survival rates markedly decrease in relation to the increase in the number of metastatic-positive nodes (5-10). Furthermore, many investigators have demonstrated that

${ }^{1}$ Gastrointestinal Cancer Surgery Division, Tianjin Medical University Cancer Hospital and City Key Laboratory of Tianjin Cancer Center; ${ }^{2}$ The Institute of Lung Cancer, Tianjin Medical University General Hospital, Tianjin, China

Correspondence: Dr Jingyu Deng, Gastric Oncology Division, Tianjin Medical University Cancer Hospital and City Key Laboratory of Tianjin

Cancer Center, Tianjin, China. Telephone 86-222-334-0123, fax 86-222-335-9984, e-mail dengery@126.com

Received for publication May 26, 2008. Accepted June 5, 2008 


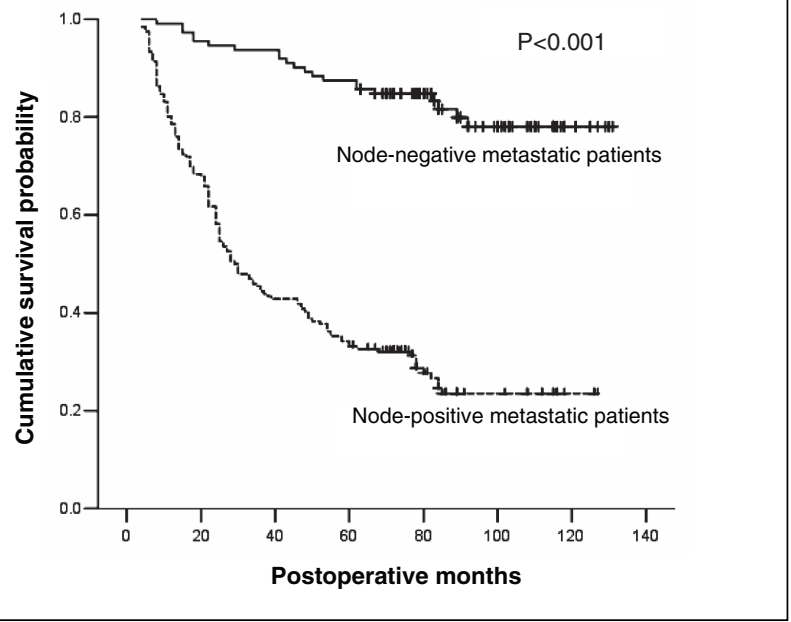

Figure 1) Overall survival of patients by status of lymph node metastasis. The Kaplan-Meier curve compares overall survival (defined as months after surgery) between gastric cancer patients with node-negative metastasis and those with node-positive metastasis

lymph node metastasis is an independent risk factor of gastric cancer recurrence following curative resection $(9,11,12)$. The overall postoperative survival of lymph node-negative gastric cancer patients is significantly longer than that of lymph nodepositive gastric cancer patients. The overall postoperative recurrence rate of lymph node-negative gastric cancer patients is significantly lower than that of lymph node-positive gastric cancer patients (13-16).

In light of these considerations, the aims of the present study were to analyze the data for elucidation of the overall prognosis of lymph node-negative gastric cancer patients following curative resection, and to use multivariate analyses to identify the independent risk factors of survival and recurrence of lymph node-negative gastric cancer patients following curative resection.

\section{METHODS}

Between January 1997 and December 2000, 308 gastric cancer patients underwent curative resection for histologically confirmed gastric carcinoma in the department of gastrointestinal cancer surgery at the Tianjin Medical University Cancer Hospital (Tianjin, China). Of these, 112 patients (36.4\%) with lymph node-negative metastasis were identified by pathological examination and evaluation. Seventy patients were men, and 42 were women. Ages ranged from 33 to 72 years, with a mean age of 54.2 years. The tumour was located in the lower one-third of the stomach in 68 cases $(60.7 \%)$, the middle one-third in 27 cases $(24.1 \%)$ and the upper one-third in 17 cases $(15.2 \%)$. According to the Japanese Classification of Gastric Carcinoma, 37 patients underwent limited lymph node dissection (D1 lymphadenectomy), and the remaining 75 patients underwent extended lymph node dissection (D2 lymphadenectomy). No patient died during the initial hospital stay or one month after surgery. Patients with fewer than 15 dissected lymph nodes after curative resection for gastric cancer were not included.

Medical records were reviewed to obtain patient data, including age at the time of surgery ( 70 years or younger, or older than 70 years), sex (male or female), location of the primary tumour (lower, middle or upper stomach), size of the primary tumour $(4 \mathrm{~cm}$ or smaller, or larger than $4 \mathrm{~cm})$, depth of the primary tumour invasion (T1, T2, T3 or T4), Lauren classification (intestinal, diffuse or mixed), presence of serosal involvement (no or yes), surgery (subtotal or total), lymphadenectomy (D1 or D2) and number of dissected lymph nodes (20 or fewer, or more than 20). After curative surgery, all patients were followed every six months for two years, then every year or until death. The median follow-up period was 84 months (range, six to 144 months). B-ultrasonography, computed tomography scans, chest $\mathrm{x}$-rays and endoscopy results were obtained with every visit.

The median OS and median recurrence-free survival were determined using the Kaplan-Meier method. The log-rank test was used to determine univariate significance. Factors that were deemed to be of potential importance by univariate analyses $(\mathrm{P}<0.05)$ were included in the multivariate analyses. Multivariate analyses were performed by means of the Cox proportional hazards model, using the forward stepwise procedure for variable selection. Hazard ratios (HRs) and 95\% CIs were generated. Significance was defined as $\mathrm{P}<0.05$. All statistical analyses were performed using a statistical analysis program package (SPSS version 13.0; SPSS Inc, USA).

\section{RESULTS}

Survival and recurrence analyses of lymph node-negative and lymph node-positive gastric cancer patients

In the present retrospective study, data from 308 consecutive patients who underwent curative resection for primary gastric cancer between January 1997 and December 2000 were examined. Of these patients, 112 (36.4\%) had lymph node-negative metastasis and 196 (63.6\%) had lymph node-positive metastasis. The five-year survival rate of lymph node-negative gastric cancer patients was significantly higher than that of lymph node-positive gastric cancer patients $(85.7 \%$ versus $33.2 \%$; log-rank $\mathrm{P}<0.001)$ following curative resection. Furthermore, the median OS of lymph node-negative gastric cancer patients was significantly longer than that of lymph node-positive gastric cancer patients following curative resection (114 versus 29 months; log-rank $\mathrm{P}<0.001$ ). The survival curves for lymph node-negative gastric cancer patients and lymph node-positive gastric cancer patients are illustrated in Figure 1. Twentyfive of 112 lymph node-negative and 144 of 196 lymph nodepositive gastric cancer patients presented with recurrence. The median recurrence-free survival of lymph node-negative gastric cancer patients was significantly longer than that of lymph node-positive gastric cancer patients following curative resection (40 versus 18 months; log-rank $\mathrm{P}<0.001$ ). The diseasefree survival curves for lymph node-negative and lymph node-positive gastric cancer patients are illustrated in Figure 2. After all recurrences were identified, the median postrecurrence survival of lymph node-negative gastric cancer patients who presented with recurrence was six months, whereas that of lymph node-positive gastric cancer patients who presented with recurrence was four months (log-rank $\mathrm{P}=0.021)$.

\section{Univariate and multivariate survival analyses of lymph node-negative gastric cancer patients}

Using univariate analyses, five factors were found to have statistically significant associations with OS of lymph nodenegative gastric cancer patients after curative surgery. These factors were sex, age, operative type, depth of primary tumour 


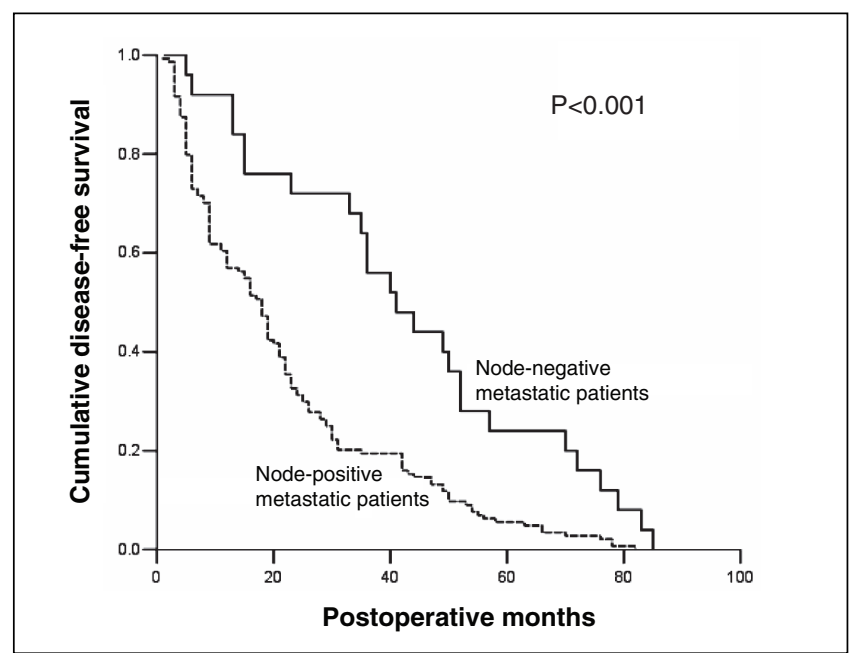

Figure 2) Disease-free survival of patients by status of lymph node metastasis. The Kaplan-Meier curve compares overall disease-free survival (defined as the time after surgery) between gastric cancer patients with node-negative metastasis and thoses with node-positive metastasis

invasion and presence of serosal involvement. The postoperative survival results of all lymph node-negative gastric cancer patients who underwent curative resection were as follows: the median OS of male patients was longer than that of female patients (119.4 versus 102.7 months; log-rank $\mathrm{P}=0.025$ ); patients who were older than 70 years of age had a significantly shorter median $O S$ than those who were 70 years of age or younger (60.0 versus 116.2 months; log-rank $\mathrm{P}=0.007$ ); patients who underwent subtotal gastrectomy had a longer median OS than those who underwent total gastrectomy (116.6 versus 91.3 months; $\log$-rank $\mathrm{P}=0.031$ ); patients with serosal involvement had a shorter median OS than those without serosal involvement (101.4 versus 126.2 months; log-rank $\mathrm{P}<0.001)$; and the more deeply the primary tumour invaded, the shorter the median OS of lymph node-negative gastric cancer patients (T4, 72.0 months; T3, 102.5 months; T2, 116.6 months; and T1, 127.9 months; logrank $\mathrm{P}=0.002$ ).

All five variables listed above were included in a multivariate Cox proportional hazards model (forward stepwise procedure) to adjust for the effects of covariates (Table 1 ). In that model, sex ( $\mathrm{HR}=0.203 ; \mathrm{P}=0.001)$, operative type $(\mathrm{HR}=0.343 ; \mathrm{P}=0.035)$ and the presence of serosal involvement $(\mathrm{HR}=0.098 ; \mathrm{P}<0.001)$ showed significant correlations with $\mathrm{OS}$ of lymph node-negative gastric cancer patients after curative surgery.

Univariate and multivariate recurrence analyses of lymph node-negative gastric cancer

Recurrence of lymph node-negative gastric cancer during followup was detected in 25 of 112 patients $(22.3 \%)$ included in the study group; 13 patients $(52.0 \%)$ showed local recurrence, six $(24.0 \%)$ showed peritoneal dissemination, two $(8.0 \%)$ showed hepatic metastases, and four (16.0\%) showed local recurrence and peritoneal dissemination simultaneously. The median disease-free survival was 40 months (95\% CI 29.8 to 50.2 months). In most cases (21 of 25 cases, $84.0 \%$ ), recurrence occurred within five years after curative surgery; in only four cases $(16.0 \%)$, recurrence occurred after five years. With univariate analysis, four factors were found to have statistically significant associations with recurrence of lymph node-negative
TABLE 1

Multivariate analysis of factors affecting the overall survival of $\mathbf{1 1 2}$ patients with lymph node-negative metastasis

\begin{tabular}{lccr}
\hline Variable & Hazard ratio & $\mathbf{9 5 \%} \mathbf{C l}$ & $\mathbf{P}$ \\
\hline Sex & 0.203 & $0.079-0.520$ & 0.001 \\
Operative type & 0.343 & $0.126-0.929$ & 0.035 \\
Presence of serosal involvement & 0.098 & $0.028-0.349$ & $<0.001$ \\
\hline
\end{tabular}

TABLE 2

Multivariate analysis of factors affecting overall recurrence of lymph node-negative metastasis in 112 patients

\begin{tabular}{lccc}
\hline Variable & Hazard ratio & $\mathbf{9 5 \%} \mathbf{C l}$ & $\mathbf{P}$ \\
\hline Lymphadenectomy & 23.578 & $3.978-139.754$ & 0.001 \\
Serosal involvement & 0.052 & $0.05-0.515$ & 0.011 \\
Number of dissected nodes & 0.108 & $0.022-0.532$ & 0.006 \\
\hline
\end{tabular}

gastric cancer patients after curative surgery. The factors were as follows: lymphadenectomy, depth of primary tumour, presence of serosal involvement and number of dissected nodes. The postoperative recurrent results in all lymph node-negative gastric cancer patients who underwent curative resection were as follows: patients who underwent D2 lymphadenectomy had a longer median disease-free survival than those who underwent D1 lymphadenectomy (49.8 versus 23.5 months; log-rank $\mathrm{P}=0.006)$; patients with serosal involvement had a shorter median disease-free survival than those without serosal involvement (36.7 versus 75.3 months; log-rank $\mathrm{P}=0.012$ ); patients with more than 20 dissected nodes had a longer median disease-free survival than those with 20 or fewer dissected nodes ( 47.5 versus 21.4 months; $\log$-rank $\mathrm{P}=0.012$ ); and the more deeply the primary tumour invaded, the shorter the median disease-free survival of lymph node-negative gastric cancer patients was (T4, 15.0 months; T3, 39.3 months; T2, 71.7 months; and T1, 85.0 months; log-rank $\mathrm{P}=0.015)$ after curative surgery.

All four variables listed above were included in a multivariate Cox proportional hazards model (forward stepwise procedure) to adjust for the effects of covariates (Table 2). In that model, lymphadenectomy $(\mathrm{HR}=23.578 ; \mathrm{P}=0.001)$, the presence of serosal involvement $(\mathrm{HR}=0.052 ; \mathrm{P}=0.011)$ and the number of dissected nodes $(\mathrm{HR}=0.108 ; \mathrm{P}=0.006)$ showed significant correlations with overall recurrence of lymph nodenegative gastric cancer patients after curative surgery.

\section{DISCUSSION}

In gastric cancer, the presence or absence of lymph node metastasis is one of the most important prognostic indicators of relative clinical and pathological factors that could influence the prognosis of patients following curative resection (1-4,17-20). Although several investigators reported that the postoperative prognosis of lymph node-negative gastric cancer patients was significantly better than that of lymph node-positive gastric cancer patients, some researchers found that a minority of lymph node-negative gastric cancer patients had recurrence and poor survival (21-25). Identification of the factors associated with survival and recurrence of lymph node-negative gastric cancer patients following curative resection is important for choosing the appropriate recipients of sequentially essential adjuvant therapy. 
Several investigators have demonstrated that older gastric cancer patients had a shorter OS than younger patients $(26-28)$. In the present study, we found a similar relationship between age and OS in all lymph node-negative gastric cancer patients by using the Kaplan-Meier method and the logrank test. However, the results of multivariate analyses showed that age was not a statistically significant independent factor of OS in lymph node-negative gastric cancer patients. Some researchers showed no differences in OS regarding sex in gastric cancer patients, regardless of tumour stages $(29,30)$. In a study performed on gastric cancer patients (31), women had a better prognosis than men. Conversely, in the present study, we found that male lymph node-negative gastric cancer patients had a longer median OS than female lymph node-negative gastric cancer patients, and identified sex as an independent factor of OS of lymph node-negative gastric cancer patients after curative surgery. Whether operative types of gastrectomy correlate with the postoperative survival of gastric cancer patients is still controversial. Many studies found that total gastrectomy offered no more survival benefits for gastric cancer patients than subtotal gastrectomy, regardless of the location of resectable lesions $(32-34)$. We demonstrated that there is a close relationship between subtotal gastrectomy and long OS of lymph node-negative gastric cancer patients after curative surgery, which was not previously reported. To our knowledge, in addition to the number of positive lymph nodes, the depth of primary tumour invasion is another independent prognostic predictor of lymph node-negative gastric cancer (35). Our results showed that the depth of primary tumour invasion could not significantly affect the

\section{REFERENCES}

1. Abe N, Watanabe T, Suzuki K, et al. Risk factors predictive of lymph node metastasis in depressed early gastric cancer. Am J Surg 2002;183:168-72.

2. Yamaguchi T, Sano T, Katai H, Sasako M, Maruyama K. Node-positive mucosal gastric cancer: A follow-up study. Jpn J Clin Oncol 2001;31:153-6.

3. de Manzoni G, Verlato G, di Leo A, et al. Perigastric lymph node metastases in gastric cancer: Comparison of different staging systems. Gastric Cancer 1999;2:201-5.

4. Chen CY, Wu CW, Lo SS, Hsieh MC, Lui WY, Shen KH. Peritoneal carcinomatosis and lymph node metastasis are prognostic indicators in patients with Borrmann type IV gastric carcinoma. Hepatogastroenterology 2002;49:874-7.

5. Manfe AZ, Segalina P, Maffei Faccioli A. [Prognostic factors in gastric cancer. Our experience and review of the literature.] Minerva Chir 2000;55:299-305.

6. Takagane A, Terashima M, Abe K, et al. Evaluation of the ratio of lymph node metastasis as a prognostic factor in patients with gastric cancer. Gastric Cancer 1999;2:122-8.

7. Yokota T, Kunii Y, Teshima S, et al. Significant prognostic factors in patients with early gastric cancer. Int Surg 2000;85:286-90.

8. Ding YB, Chen GY, Xia JG, Zang XW, Yang HY, Yang L. Association of VCAM-1 overexpression with oncogenesis, tumor angiogenesis and metastasis of gastric carcinoma. World J Gastroenterol 2003;9:1409-14.

9. Pan W, Ishii H, Ebihara Y, Gobe G. Prognostic use of growth characteristics of early gastric cancer and expression patterns of apoptotic, cell proliferation, and cell adhesion proteins. J Surg Oncol 2003;82:104-10.

10. Coburn NG, Swallow CJ, Kiss A, Law C. Significant regional variation in adequacy of lymph node assessment and survival in gastric cancer. Cancer 2006;107:2143-51.

11. Nakamura K, Morisaki T, Sugitani A, et al. An early gastric carcinoma treatment strategy based on analysis of lymph node metastasis. Cancer 1999;85:1500-5. recurrence of lymph node-negative gastric cancer patients until the serosa of the stomach was infiltrated by a primary tumour. Similar results were reported by other authors $(25,36,37)$. Although Japanese surgeons routinely perform extended lymphadenectomy for gastric cancer patients without distant metastasis, many western investigators have reported that D2 or more extended lymphadenectomy could not improve the prognosis of gastric cancer significantly compared with D1 lymphadenectomy, which is generally accepted by surgeons in western countries (38-43). Nevertheless, other investigators have stated that D2 lymph node dissection might improve the survival of patients with lymph node-negative gastric carcinoma $(25,44,45)$. In the present study, we found that D2 lymphadenectomy did not contribute to extending OS, but did contribute to extending disease-free survival of lymph node-negative gastric cancer patients. Many studies demonstrated that the number of dissected lymph nodes was not relative to the prognosis of gastric cancer patients after curative surgery (46-48). Our results revealed that the number of dissected lymph nodes did not affect OS but did affect disease-free survival.

\section{CONCLUSIONS}

Male lymph node-negative gastric cancer patients who underwent subtotal gastrectomy and presented without serosal invasion had long-term survival after curative surgery for gastric cancer. Meanwhile, D1 lymphadenectomy, few dissected lymph nodes and serosal invasion were the independent risk factors of recurrence for lymph node-negative gastric cancer after curative surgery for gastric cancer.
12. Kodera Y, Yamamura Y, Shimizu Y, et al. Lymph node status assessment for gastric carcinoma: Is the number of metastatic lymph nodes really practical as a parameter for $\mathrm{N}$ categories in the TNM Classification? Tumor Node Metastasis. J Surg Oncol 1998;69:15-20.

13. Sarela AI, Turnbull AD, Coit DG, Klimstra D, Brennan MF, Karpeh MS. Accurate lymph node staging is of greater prognostic importance than subclassification of the T2 category for gastric adenocarcinoma. Ann Surg Oncol 2003;10:783-91.

14. Hochwald SN, Kim S, Klimstra DS, Brennan MF, Karpeh MS. Analysis of 154 actual five-year survivors of gastric cancer. J Gastrointest Surg 2000;4:520-5.

15. Guadagni S, Catarci M, Kinoshita T, Valenti M, De Bernardinis G, Carboni M. Causes of death and recurrence after surgery for early gastric cancer. World J Surg 1997;21:434-9.

16. Nakamoto J, Torisu R, Aoki R, et al. Clinicopathological evaluation of biological behavior of submucosal invasive gastric carcinomas: Relationship among lymph node metastasis, mucin phenotype and proliferative activity. J Med Invest 2007;54:99-108.

17. Bozzetti F, Bonfanti G, Morabito A, et al. A multifactorial approach for the prognosis of patients with carcinoma of the stomach after curative resection. Surg Gynecol Obstet 1986;162:229-34.

18. Maruyama K. The most important prognostic factors for gastric cancer patients. Scand J Gastroenterol 1987;22:63-68.

19. Adachi Y, Ogawa Y, Sasaki Y, Yukaya H, Mori M, Sugimachi K. A clinicopathologic study of gastric carcinoma with reference to age of patients. J Clin Gastroenterol 1994;18:287-90.

20. Siewert JR, Bottcher K, Stein HJ, Roder JD. Relevant prognostic factors in gastric cancer: Ten-year results of the German Gastric Cancer Study. Ann Surg 1998;228:449-61.

21. Adachi Y, Mori M, Maehara Y, Kitano S, Sugimachi K. Prognostic factors of node-negative gastric carcinoma: Univariate and multivariate analyses. J Am Coll Surg 1997;184:373-7. 
22. Maehara Y, Tomoda M, Tomisaki S, et al. Surgical treatment and outcome for node-negative gastric cancer. Surgery 1997;121:633-9.

23. Bruno L, Nesi G, Montinaro F, et al. Clinicopathologic characteristics and outcome indicators in node-negative gastric cancer. J Surg Oncol 2000;74:30-2.

24. Hyung WJ, Lee JH, Choi SH, Min JS, Noh SH. Prognostic impact of lymphatic and/or blood vessel invasion in patients with node-negative advanced gastric cancer. Ann Surg Oncol 2002;9:562-7.

25. Kim DY, Seo KW, Joo JK, et al. Prognostic factors in patients with node-negative gastric carcinoma: A comparison with node-positive gastric carcinoma. World J Gastroenterol 2006;12:1182-6.

26. Adachi Y, Oshiro T, Mori M, Maehara Y, Sugimachi K. Tumor size as a simple prognostic indicator for gastric carcinoma. Ann Surg Oncol 1997;4:137-40.

27. Houry S, Amenabar J, Rezvani A, Huguier M. Should patients over 80 years old be operated on for colorectal or gastric cancer? Hepatogastroenterology 1994:41:521-5.

28. Takeda J, Tanaka T, Koufuji K, Kodama I, Tsuji Y, Kakegawa T. Gastric cancer surgery in patients aged at least 80 years old. Hepatogastroenterology 1994:41:516-20.

29. Fuchs CS, Mayer RJ. Gastric carcinoma. N Engl J Med 1995;333:32-41.

30. Jonasson L, Hallgrimsson J, Sigvaldason H, et al. Gastric cancer in Iceland: A retrospective study of resected gastric specimens in a high-risk country during 30 years (1960-1989). Int J Cancer 1994;57:793-8

31. Kim JP, Lee JH, Kim SJ, Yu HJ, Yang HK. Clinicopathologic characteristics and prognostic factors in 10783 patients with gastric cancer. Gastric Cancer 1998;1:125-33.

32. Gouzi JL, Huguier M, Fagniez PL, et al. Total versus subtotal gastrectomy for adenocarcinoma of the gastric antrum. A French prospective controlled study. Ann Surg 1989;209:162-6.

33. Bozzetti F, Marubini E, Bonfanti G, Miceli R, Piano C, Gennari L. Subtotal versus total gastrectomy for gastric cancer: Five-year survival rates in a multicenter randomized Italian trial. Italian Gastrointestinal Tumor Study Group. Ann Surg 1999;230:170-8.

34. Harrison LE, Karpeh MS, Brennan MF. Total gastrectomy is not necessary for proximal gastric cancer. Surgery 1998;123:127-30.

35. Mori M, Sugimachi K. Clinicopathologic studies of gastric carcinoma. Semin Surg Oncol 1990;6:19-27.
36. Kooby DA, Suriawinata A, Klimstra DS, Brennan MF, Karpeh MS Biologic predictors of survival in node-negative gastric cancer. Ann Surg 2003;237:828-35.

37. Abe S, Shiraishi M, Nagaoka S, Yoshimura H, Dhar DK, Nakamura T. Serosal invasion as the single prognostic indicator in stage IIIA (T3N1M0) gastric cancer. Surgery 1991;109:582-8.

38. Irvin TT, Bridger JE. Gastric cancer: An audit of 122 consecutive cases and results of R1 gastrectomy. Br J Surg 1988;75:106-9.

39. Herberer G, Teichman RK, Kramling HJ, Gunther B. Results of gastric resection for carcinoma of the stomach: The European experience. World J Surg 1988;12:374-81.

40. Dent DM, Madden MV, Price SK. Randomized comparison of R1 and R2 gastrectomy for gastric carcinoma. Br J Surg 1988;75:110-2.

41. Miwa K, Miyazaki I, Sahara H, et al. Rationale for extensive lymphadenectomy in early gastric carcinoma. Br J Cancer 1995; 72:1518-24.

42. Bonenkamp JJ, Hermans J, Sasako M, et al; Dutch Gastric Cancer Group. Extended lymph-node dissection for gastric cancer. N Engl J Med 1999;340:908-14.

43. Cuschieri A, Fayers P, Fielding J, et al. Postoperative morbidity and mortality after D1 and D2 resections for gastric cancer: Preliminary results of the MRC randomised controlled surgical trial. Lancet 1996;347:995-9.

44. Adachi Y, Oshiro T, Mori M, Maehara Y, Sugimachi K. Tumor size as a simple prognostic indicator for gastric carcinoma. Ann Surg Oncol $1997 ; 4: 137-40$

45. Harrison LE, Karpeh MS, Brennan MF. Extended lymphadenectomy is associated with a survival benefit for node-negative gastric cancer. J Gastrointest Surg 1998;2:126-31.

46. Siewert JR, Böttcher K, Stein HJ, Roder JD. Relevant prognostic factors in gastric cancer: Ten-year results of the German Gastric Cancer Study. Ann Surg 1998;228:449-61.

47. Adachi Y, Shiraishi N, Suematsu T, Shiromizu A, Yamaguchi K, Kitano S. Most important lymph node information in gastric cancer: Multivariate prognostic study. Ann Surg Oncol 2000;7:503-7.

48. Marchet A, Mocellin S, Ambrosi A, et al; Italian Research Group for Gastric Cancer (IRGGC). The ratio between metastatic and examined lymph nodes ( $\mathrm{N}$ ratio) is an independent prognostic factor in gastric cancer regardless of the type of lymphadenectomy: Results from an Italian multicentric study in 1853 patients. Ann Surg 2007;245:543-52. 


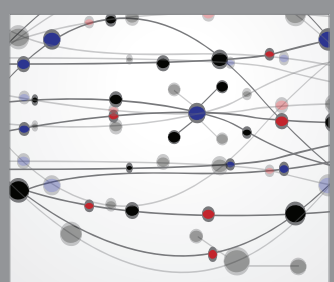

The Scientific World Journal
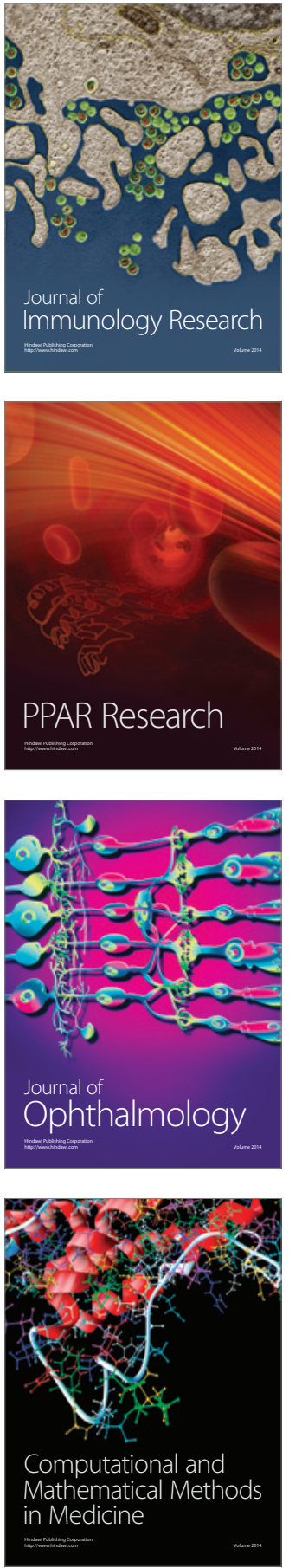

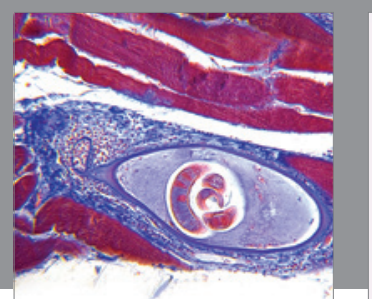

Gastroenterology Research and Practice

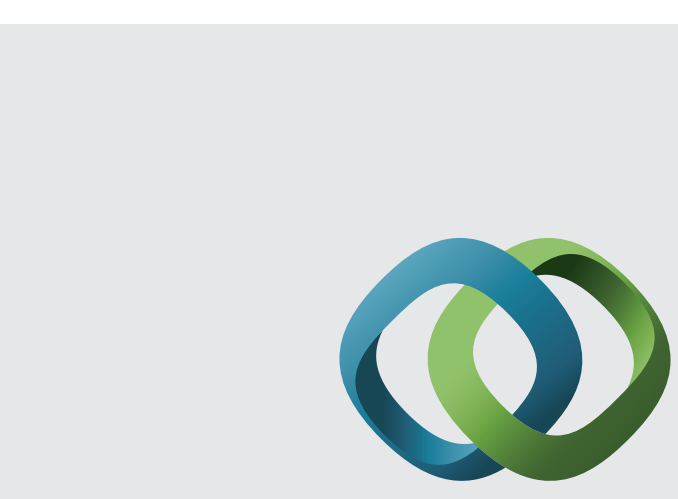

\section{Hindawi}

Submit your manuscripts at

http://www.hindawi.com
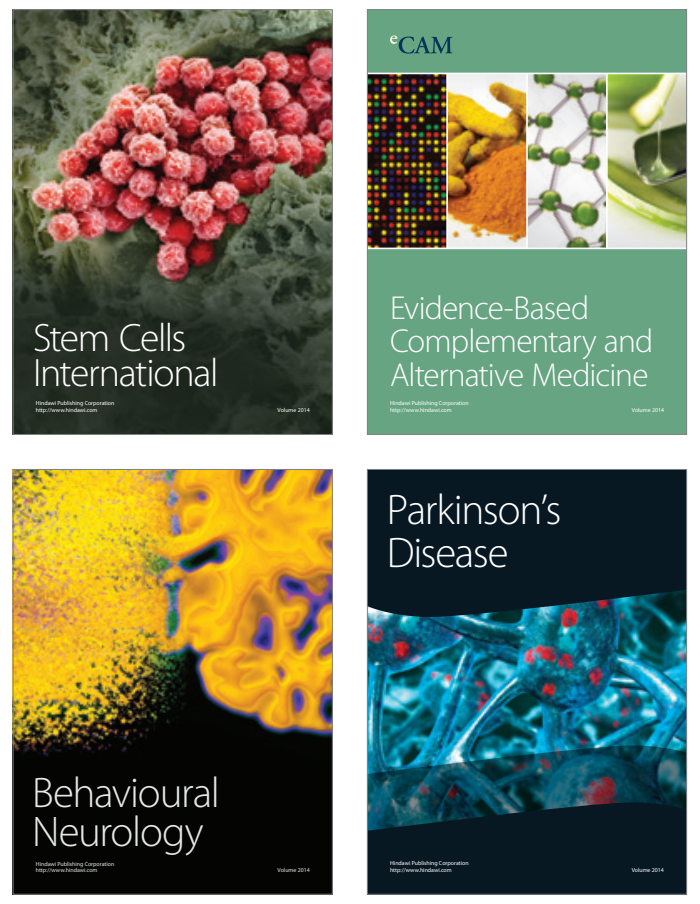
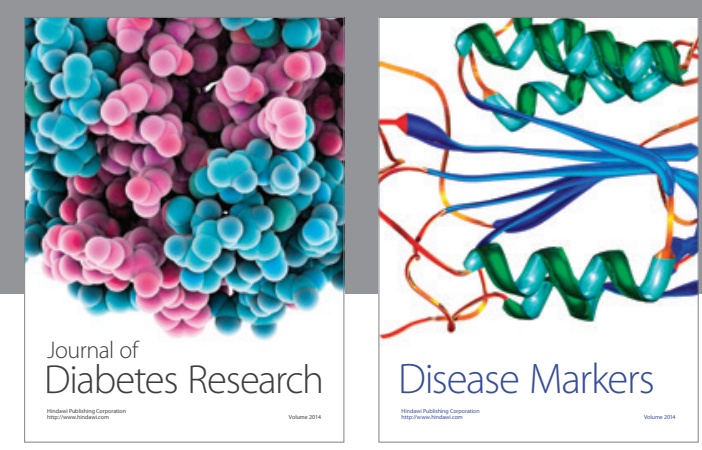

Disease Markers
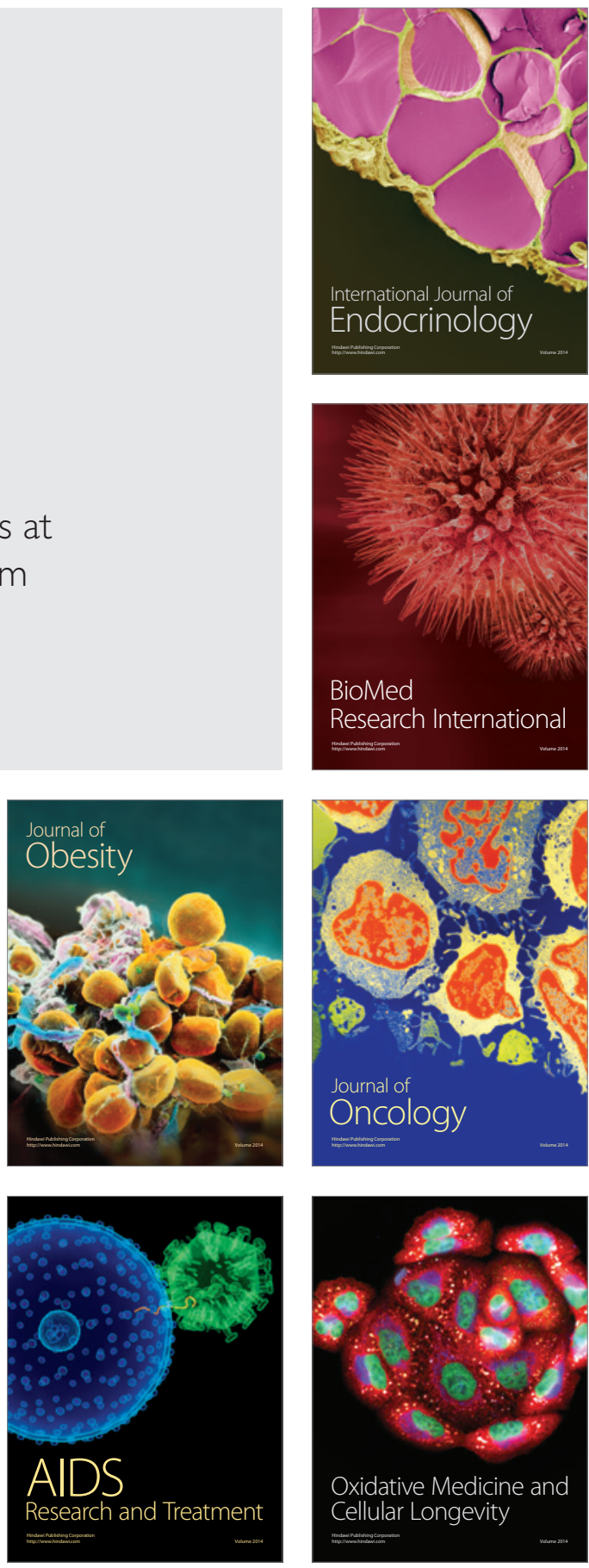